\title{
Effect of Bench Hood Exhaust Usage on Indoor Air Quality in a Chemical Laboratory
}

\author{
Ayman A. Shaaban, Samy M. Morcos, Essam E. Khalil \\ and Mahmoud A. Fouad
}

Department of Mechanical Power Engineering, Cairo University, Giza, Egypt

Email: khalile1@asme.org

Keywords: Ventilation, IAQ, ACH, Contaminant, CFD

\begin{abstract}
Indoor air quality inside chemical laboratories subjected to gaseous contaminants was investigated numerically throughout the current research using Ansys Fluent 13. The lab is 4.8 $\mathrm{m}(\mathrm{L}) * 4.3 \mathrm{~m}(\mathrm{~W}) * 2.73 \mathrm{~m}(\mathrm{H})$. The model was built and mesh was generated using Gambit 2.2.30 yielding around 1.4 million cells. To ensure the reliability of the Computational Fluid Dynamics (CFD) model validation was done against experimental data of three cases done by Jin et al. [1]. The model could simulate accurately contaminant mole fraction to the order of 10 Indoor air quality inside chemical laboratories subjected to gaseous contaminants was investigated numerically throughout the current research using Ansys Fluent 13. The lab is $4.8 \mathrm{~m}(\mathrm{~L}) * 4.3 \mathrm{~m}(\mathrm{~W}) * 2.73 \mathrm{~m}$ $(\mathrm{H})$. The model was built and mesh was generated using Gambit 2.2.30 yielding around 1.4 million cells. To ensure the reliability of the Computational Fluid Dynamics (CFD) model validation was done against experimental data of three cases done by Jin et al. [1]. The model could simulate accurately contaminant mole fraction to the order of 10
\end{abstract}

\section{INTRODUCTION}

Chemical exposures have always been a concern in occupational health. People working in laboratories are more likely to be exposed to hazardous chemicals. As a result, they are expected to have a higher risk of developing serious diseases as leukemia, lymphatic cancer and brain cancer. A well designed ventilation system inside chemical laboratories will ensure the occupants' safety and yield energy savings by avoiding unnecessarily high values of Air Changes per Hour (ACH). Decreasing the ventilation rate from 12 to $6 \mathrm{ACH}$ led to annual energy saving of $49 \%$ in a study done by Memarzadeh [2] on a typical laboratory located in Washington DC.

CFD has proved to be a good alternative to accurately simulate contaminant dispersion in closed environment. Cheong et al. [3] investigated contaminant distribution inside office using CFD employing RNG k- $\varepsilon$ turbulence model. Validation was done against experimental data. The error varied from $-4.4 \%$ to $-16.5 \%$. Rohdin and Moshfegh [4] used numerical simulation to study ventilation in industrial premises. The average temperature deviation between the simulated and measured results was $1.1 \mathrm{C}$, while the average velocity deviation was $0.11 \mathrm{~m} / \mathrm{s}$.

Chung et al. [5] investigated the performance of local ventilated hood in a general ventilation environment. The hood capture efficiency was inversely proportional with the air change rate. The turbulence intensity was found to play important role. Doubling the turbulence intensity may lead to reduction of the hood capture efficiency by $1 / 3$ to $1 / 2$ of its value. Ceiling inlet yielded more stable concentration profiles with time as compared to the wall inlet. This advantage is supported by Lee et al. [6] who showed that ceiling diffuser produced lower contaminant concentration as compared to wall jet with higher ventilation effectiveness.

Chau et al. [7] investigated Local Exhaust Ventilation (LEV) in a hospital ward to capture infectious aerosols. Using LEV ensured that no particles reached Health Care Worker (HCW) breathing zone or deposited on his body. This prevented both direct and indirect infection. Using LEV decreased the particles suspension time to the order of $10 \mathrm{~s}$.

Jin et al. [1] investigated the bench hood usage to effectively capture the contaminants locally before spreading within a chemical laboratory. Both local and average contaminant concentrations 
obviously reduced after employing the bench hood exhaust for either 12 or $6 \mathrm{ACH}$ for two different spill locations.

\section{MATHEMATICAL MODELING}

The governing equations are those equations which govern the fluid motion in time and space. The governing equations must be solved to determine pressure, three dimensional velocity vector, temperature and species concentration at each point in the flow field. The governing equations in our model which simulates ventilation inside chemical laboratories are mass conservation (continuity), momentum conservation, energy conservation and species transport equation. These equations have the following general form:

$$
\frac{\partial}{\partial t} \rho \phi+\frac{\partial}{\partial x_{i}} \rho U_{i} \phi=\frac{\partial}{\partial x_{i}}\left(\Gamma_{\phi} \frac{\partial \Phi}{\partial x_{i}}\right)+S_{\phi}
$$

Where $\Gamma_{\phi}$ is the diffusion coefficient and $S_{\phi}$ represents source terms of the dependant variable $\phi$. RNG k- $\varepsilon$ is the employed turbulence model in the current research.

\section{ASSESSMENT AND VALIDATION}

To ensure the reliability of the used CFD model, validation was done at first against experimental data gathered by Jin et al. [1] while studying a chemical laboratory subjected to accidental spill. Three case studies with three different ventilation rates $(12,9$ and $6 \mathrm{ACH})$ were done. The effect of different turbulence models was first investigated. Standard k-Epsilon (SKE), Realizable k-Epsilon (RKE) and Renormalization Group K-Epsilon (RNG) turbulence models were used in the first case (12 ACH). RNG shows best fit with experimental data. So RNG model will be used in the rest of this research.

The average absolute error between the simulation and experimental data is $0.035 \mathrm{ppm}$. The average absolute percentage error of the nine data is $9.4 \%$. It is obvious that the cases deal with very small concentrations of the tracer gas. The error is acceptable taking into consideration the difficulty of simulating such a resolution (mole fraction of order 10-7).

\section{PHYSICAL ROOM MODEL}

The lab has the dimensions of $4.3 \mathrm{~m} * 4.8 \mathrm{~m} * 2.73 \mathrm{~m}$ as depicted in figure 1 . The walls are well insulated. The laboratory has two desks and two shelves, as well as three pieces of heated boxes on the desks to simulate different equipment with heat input each of $84 \mathrm{~W}$. Three humans simulate personnel working in the laboratory. Human dimensions are in the guide of optimum proportions proposed by Srebric et al. [8]. As it has been assumed that the occupant's metabolic rate is 116 $\mathrm{W} / \mathrm{m} 2$ (2 Met), mean skin temperature is equivalent to $32.5^{\circ} \mathrm{C}$ according to Guyton [9]. Three different spill locations are studied: on the bench top, on the floor near the bench and on the floor in a far corner. The air is supplied through ceiling jet. Two wall exhausts and two bench hood exhausts are available in the model. The contaminant gas tested is Sulphur Hexafluoride (SF6). 

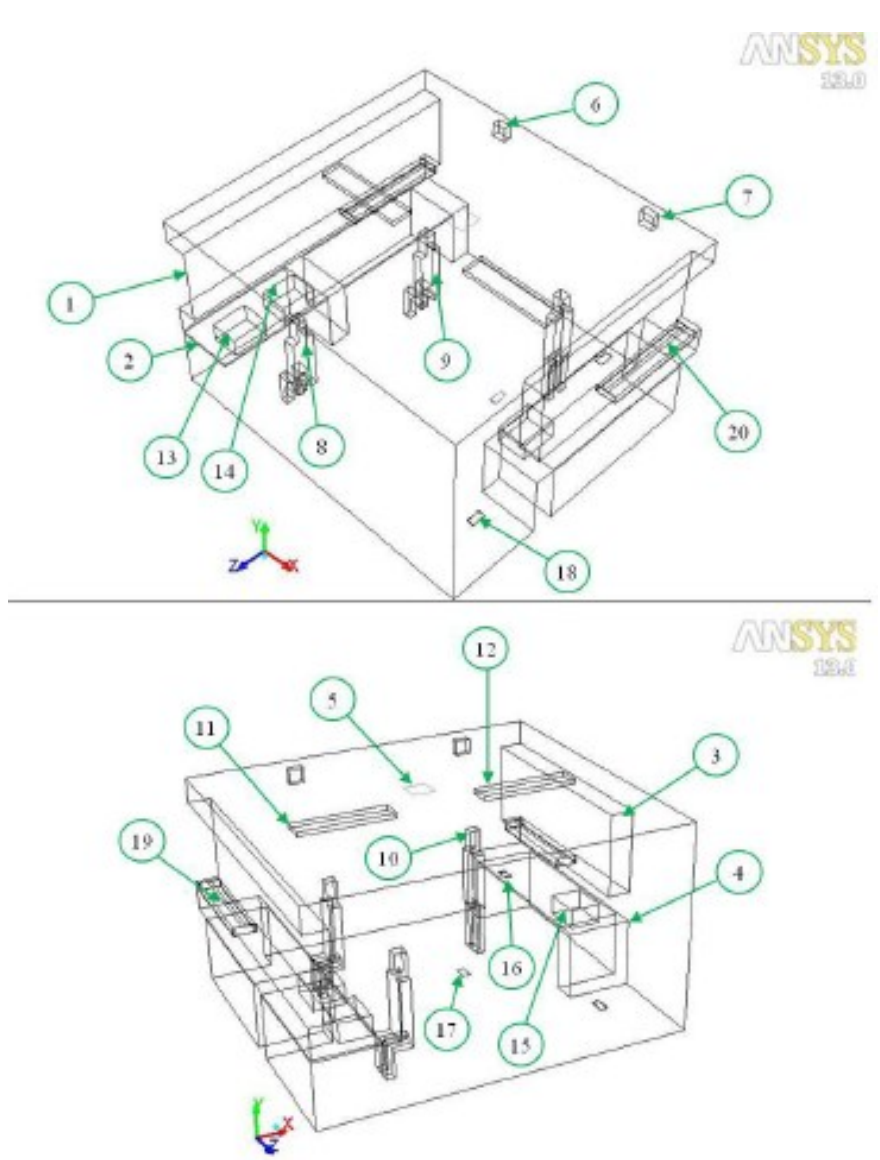

(1) Shelf 1 (2)Desk 1 (3) Shelf 2 (4)Desk 2 (5)Ceiling Supply (6)Wall Exhaust 1 (7)Wall Exhaust 2 (8) Occupant 19 Occupant 2 (10)Occupant 3 (11)Light 1 (12)Light 2 (13)Equipment 1 (14)Equipment 2 (15)Equipment 3 (16)Spill 1 (17)Spill 2(18)Spill 3(19) Bench Exhaust 1 (20)Bench Exhaust 2

Figure 1: The layout of the model of the chemical laboratory

\section{RESULTS AND CASE STUDIES}

The following cases as shown in table 1 will be studied throughout the current research. The effect of bench hood usage will be investigated. For $12 \mathrm{ACH}$, spill occurring in location 1 on the bench top will be investigated without and with bench exhaust (cases 1 and 2) and also for spill 2 on the floor near the standing occupant in front of the bench (cases 3 and 4). For $6 \mathrm{ACH}$, spill occurring in location 1 will be investigated without and with bench exhaust (cases 5 and 6) and also for spill 2 (cases 7 and 8).

Table 1: Case studies in the current research

\begin{tabular}{|c|c|c|c|c|c|c|}
\hline Case No. & $\mathrm{ACH}$ & Wall Exhaust 1 & Wall Exhaust 2 & Bench Exhaust 2 & Spill Location & Gaseous Contaminant \\
\hline 1 & 12 & 12 & - & - & 1 & $\mathrm{SF}_{6}$ \\
\hline 2 & 12 & 6 & - & 6 & 1 & $\mathrm{SF}_{6}$ \\
\hline 3 & 12 & 12 & - & - & 2 & $\mathrm{SF}_{6}$ \\
\hline 4 & 12 & 6 & - & 6 & 2 & $\mathrm{SF}_{6}$ \\
\hline 5 & 6 & 6 & - & - & 1 & $\mathrm{SF}_{6}$ \\
\hline 6 & 6 & 3 & - & 3 & 1 & $\mathrm{SF}_{6}$ \\
\hline 7 & 6 & 6 & - & - & 2 & $\mathrm{SF}_{6}$ \\
\hline 8 & 6 & 3 & - & 3 & 2 & $\mathrm{SF}_{6}$ \\
\hline
\end{tabular}




\subsection{Bench Hood Usage with 12 ACH}

For case 1, contours of Sulphur Hexafluoride concentration in ppm in the plane of sitting occupant at height of $1.1 \mathrm{~m}$ in the laboratory is depicted in figure 2 with average concentration of $4.11 \mathrm{ppm}$. The average of $\mathrm{SF}_{6}$ concentration in the plane of standing occupants at height of $1.7 \mathrm{~m}$ is $4.12 \mathrm{ppm}$. For case 2, Sulphur Hexafluoride concentration contours in ppm in the plane of sitting occupants is presented in figure 3 with average concentration of $1.48 \mathrm{ppm}$. The average of $\mathrm{SF}_{6}$ concentration in the plane of standing occupant is $0.27 \mathrm{ppm}$.

For case 3, contours of Sulphur Hexafluoride concentration in ppm in the plane of sitting occupant at height of $1.1 \mathrm{~m}$ in the laboratory is shown in figure 4 with average concentration of $4.28 \mathrm{ppm}$. The average of $\mathrm{SF}_{6}$ concentration in the plane of standing occupants at height of $1.7 \mathrm{~m}$ is $4.17 \mathrm{ppm}$. For case 4, Sulphur Hexafluoride concentration contours in ppm in the plane of sitting occupants is presented in figure 5 with average concentration of $2.68 \mathrm{ppm}$. The average of $\mathrm{SF}_{6}$ concentration in the plane of standing occupant is $2.52 \mathrm{ppm}$.

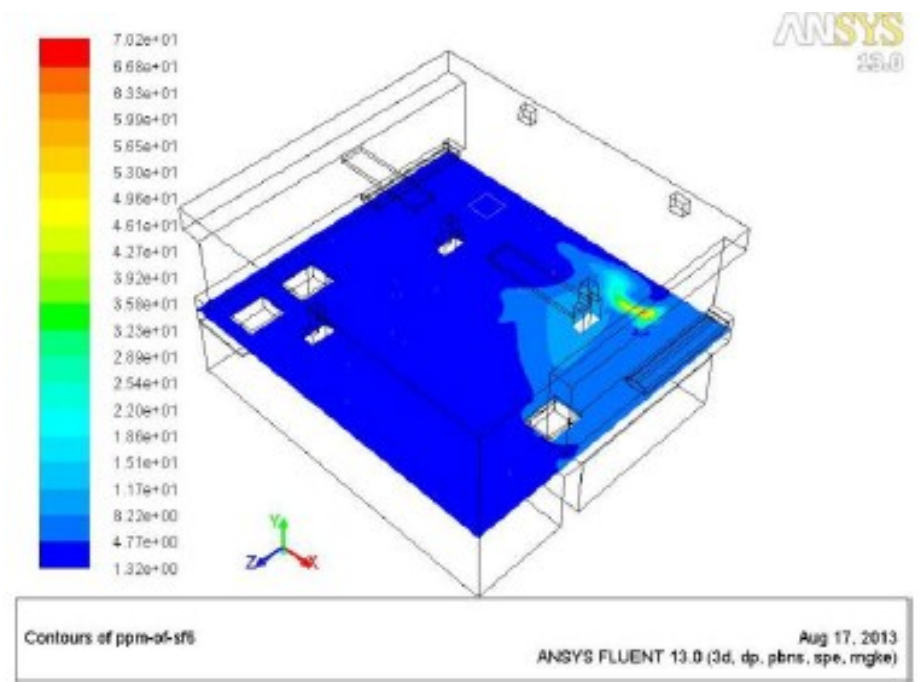

Figure 2: Contours of $\mathrm{SF}_{6}$ concentration in ppm in the plane of sitting occupant at height of $1.1 \mathrm{~m}$ in the laboratory in case 1

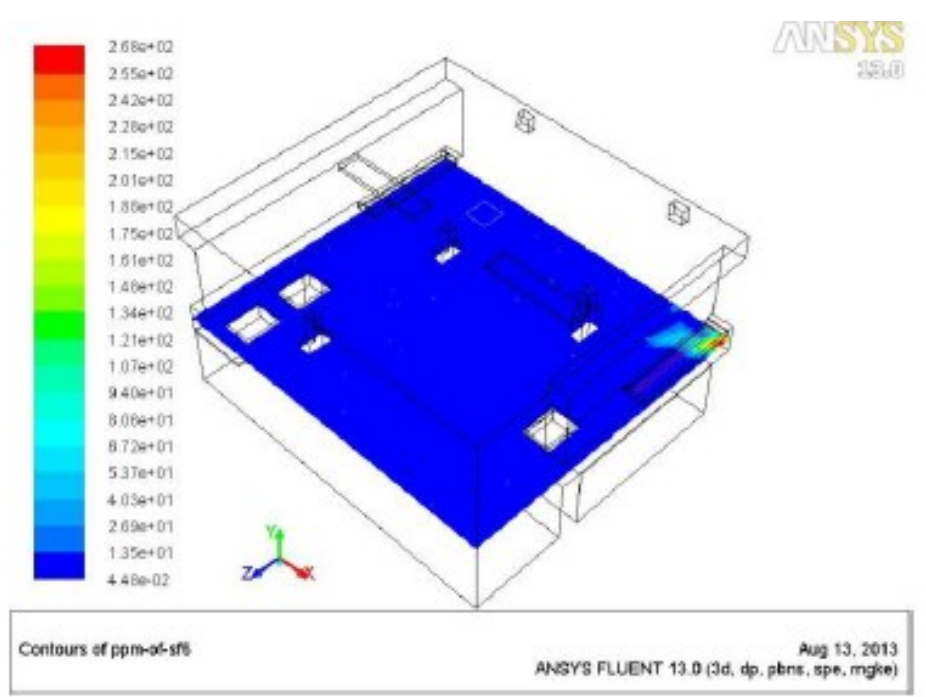

Figure 3: Contours of $\mathrm{SF}_{6}$ concentration in ppm in the plane of sitting occupant at height of $1.1 \mathrm{~m}$ in the laboratory in case 2 


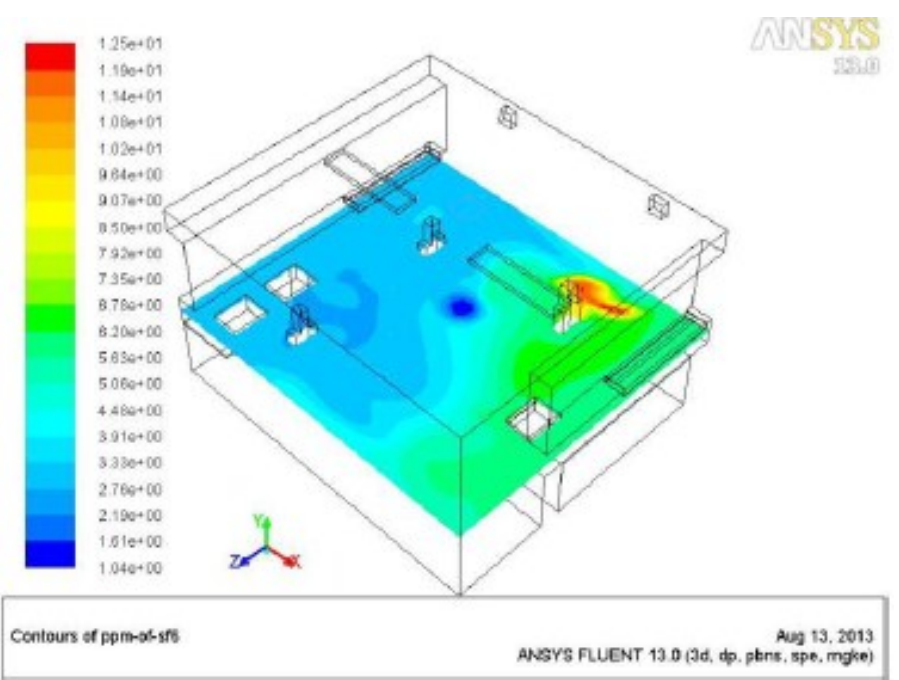

Figure 4: Contours of ${ }_{\mathrm{SF} 6}$ concentration in ppm in the plane of sitting occupant at height of $1.1 \mathrm{~m}$ in the laboratory in case 3

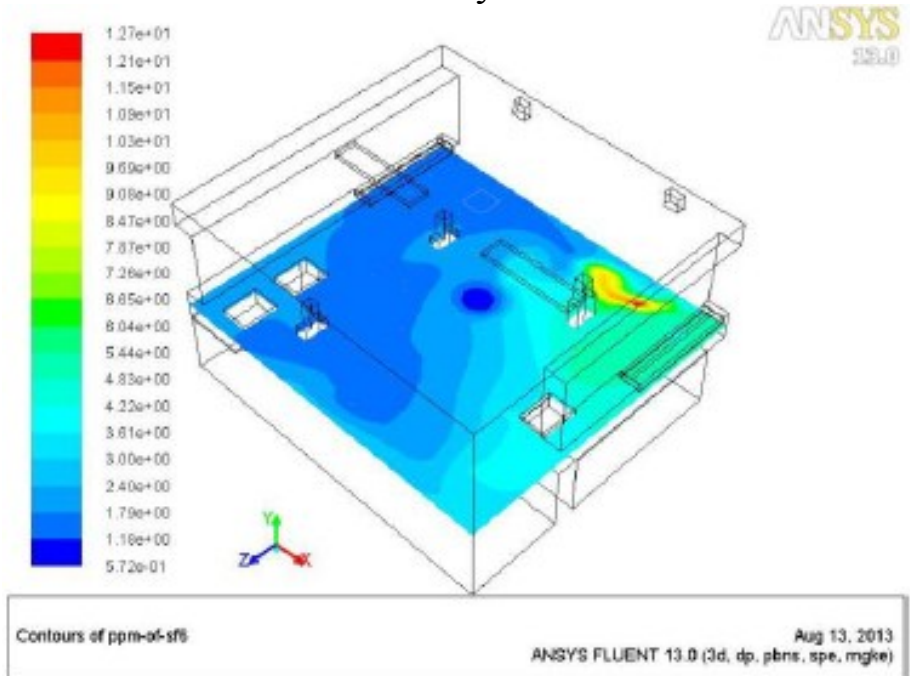

Figure 5: Contours of $\mathrm{SF}_{6}$ concentration in $\mathrm{ppm}$ in the plane of sitting occupant at height of $1.1 \mathrm{~m}$ in the laboratory in case 4

Average contaminant concentration for cases 1 and 2 is depicted in figure 6 . After using the bench hood exhaust the $1.1 \mathrm{~m}$ average contaminant concentration decreases by $64 \%, 1.7 \mathrm{~m}$ average concentration decreases by $93.5 \%$ and the total average concentration decreases by $82.7 \%$. Average contaminant concentration for cases 3 and 4 is shown in figure 7 . After employing the bench hood exhaust the $1.1 \mathrm{~m}$ average contaminant concentration decreases by $37.4 \%, 1.7 \mathrm{~m}$ average concentration decreases by $39.6 \%$ and the total average concentration decreases by $35.6 \%$.

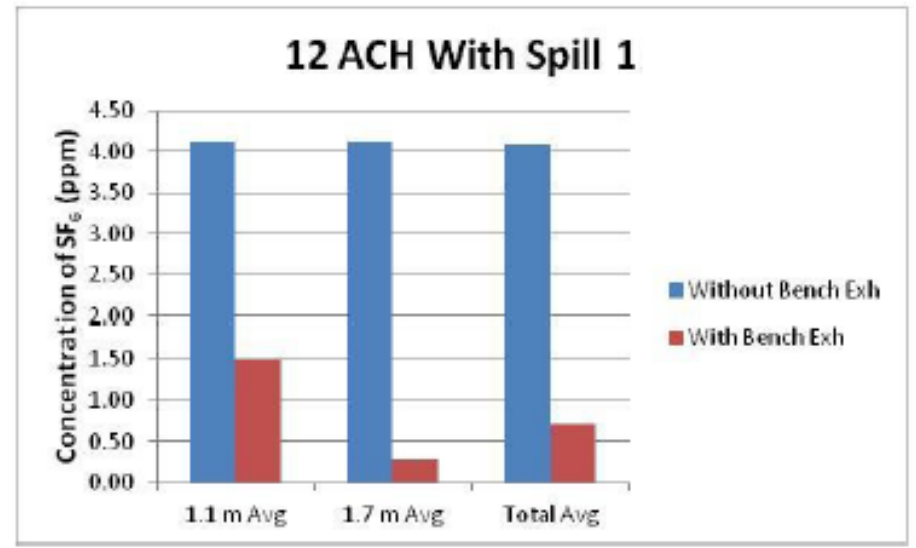

Figure 6: Average contaminant concentration without and with bench hood exhaust under $12 \mathrm{ACH}$ with spill 1 corresponding to cases $1 \& 2$ 


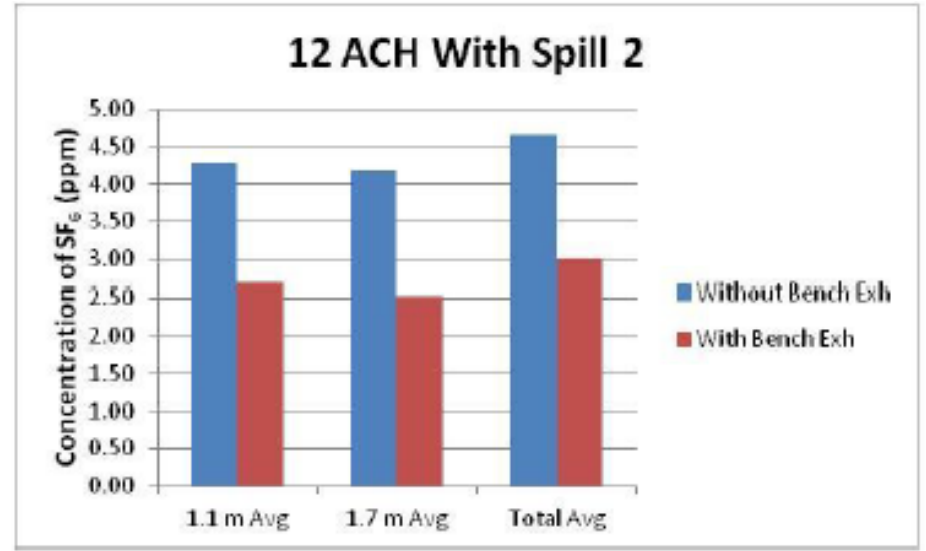

Figure 7: Average contaminant concentration without and with bench hood exhaust under $12 \mathrm{ACH}$ with spill 2 corresponding to cases $3 \& 4$

\subsection{Bench Hood Usage with 6 ACH}

For case 5, contours of Sulphur Hexafluoride concentration in ppm in the plane of sitting occupant at height of $1.1 \mathrm{~m}$ in the laboratory is depicted in figure 8 with average concentration of $9.85 \mathrm{ppm}$. The average of $\mathrm{SF}_{6}$ concentration in the plane of standing occupants at height of $1.7 \mathrm{~m}$ is $9.21 \mathrm{ppm}$. For case 6, Sulphur Hexafluoride concentration contours in ppm in the plane of sitting occupants is presented in figure 9 with average concentration of $5.64 \mathrm{ppm}$. The average of $\mathrm{SF}_{6}$ concentration in the plane of standing occupant is $1.97 \mathrm{ppm}$.

For case 7, contours of Sulphur Hexafluoride concentration in ppm in the plane of sitting occupant at height of $1.1 \mathrm{~m}$ in the laboratory is shown in figure 10 with average concentration of $9.25 \mathrm{ppm}$. The average of $\mathrm{SF}_{6}$ concentration in the plane of standing occupants at height of $1.7 \mathrm{~m}$ is $8.93 \mathrm{ppm}$. For case 8, Sulphur Hexafluoride concentration contours in ppm in the plane of sitting occupants is presented in figure 11 with average concentration of $5.08 \mathrm{ppm}$. The average of SF6 concentration in the plane of standing occupant is $4.79 \mathrm{ppm}$. Using the bench hood exhaust managed to capture the contaminants locally before spreading in the room.

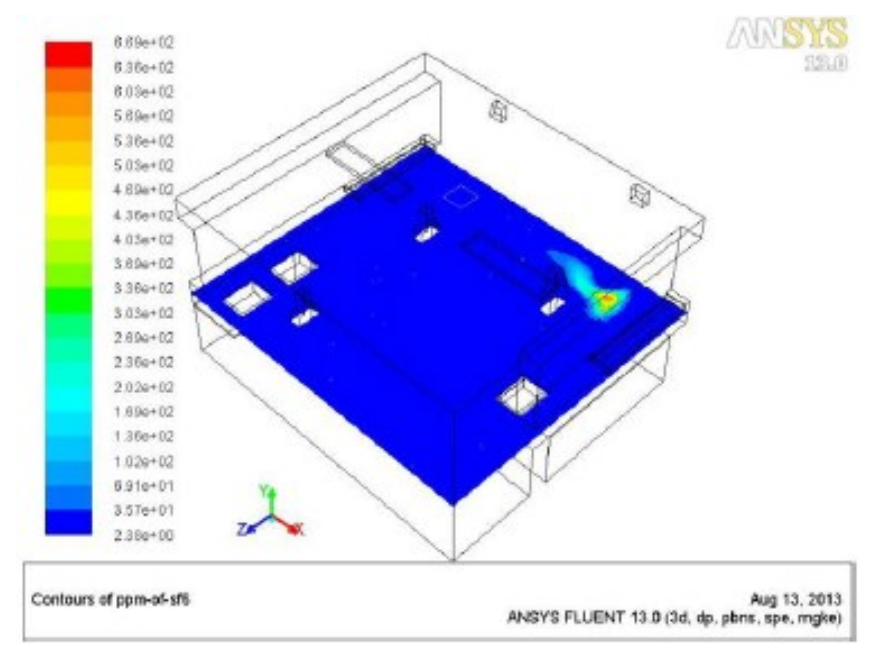

Figure 8: Contours of $\mathrm{SF}_{6}$ concentration in $\mathrm{ppm}$ in the plane of sitting occupant at height of $1.1 \mathrm{~m}$ in the laboratory in case 5 


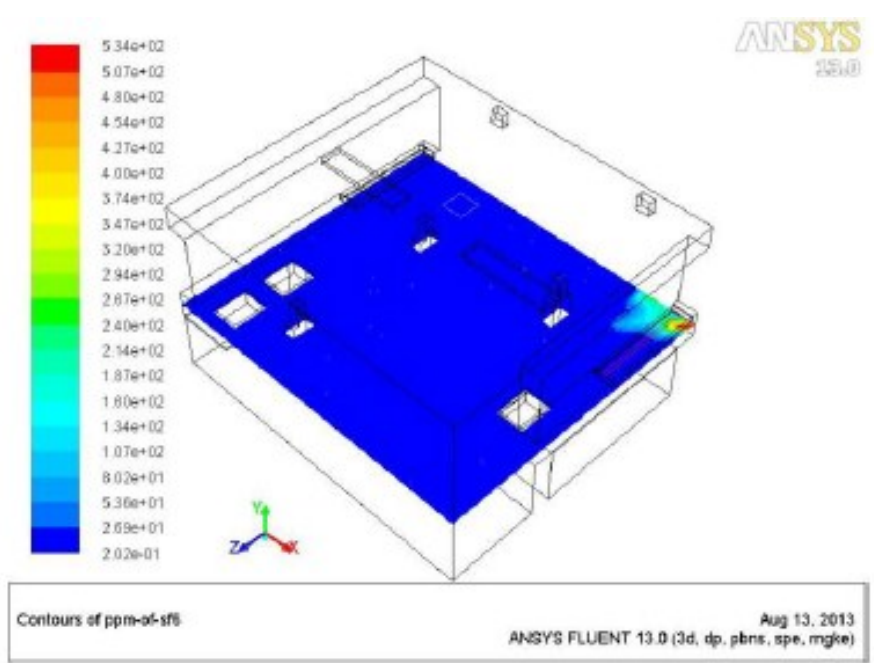

Figure 9: Contours of $\mathrm{SF}_{6}$ concentration in $\mathrm{ppm}$ in the plane of sitting occupant at height of $1.1 \mathrm{~m}$ in the laboratory in case 6

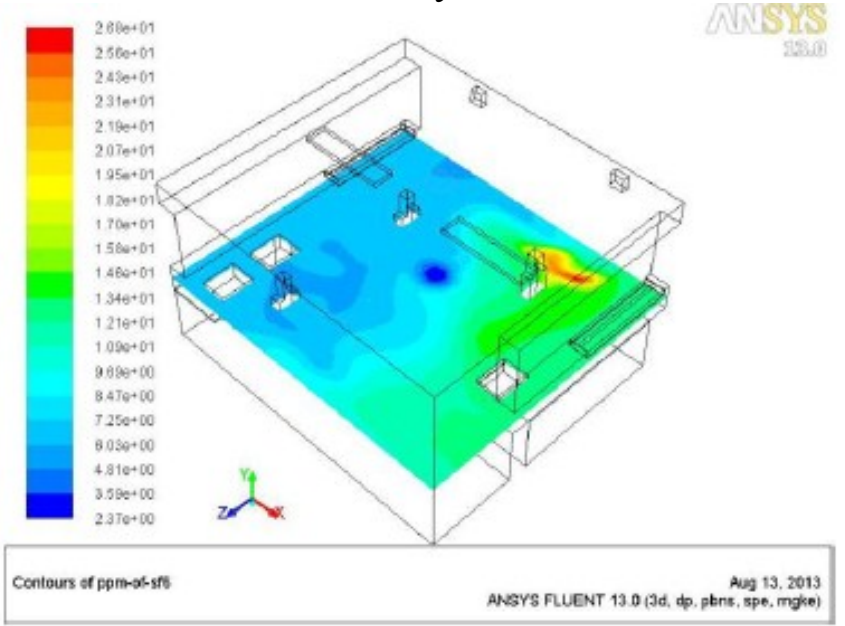

Figure 10: Contours of $\mathrm{SF}_{6}$ concentration in ppm in the plane of sitting occupant at height of $1.1 \mathrm{~m}$ in the laboratory in case 7

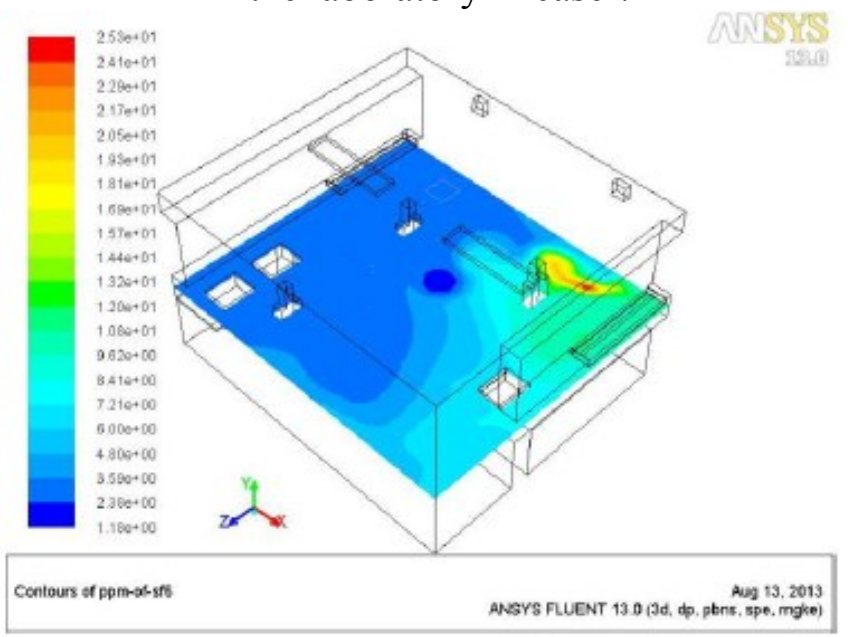

Figure 11: Contours of $\mathrm{SF}_{6}$ concentration in ppm in the plane of sitting occupant at height of $1.1 \mathrm{~m}$ in the laboratory in case 8

Average contaminant concentration for cases 5 and 6 is presented in figure 12. After using the bench hood exhaust the $1.1 \mathrm{~m}$ average contaminant concentration decreases by $42.7 \%, 1.7 \mathrm{~m}$ average concentration decreases by $78.6 \%$ and the total average concentration decreases by $70 \%$. Average contaminant concentration for cases 7 and 8 is depicted in figure 13. After employing the bench hood exhaust the $1.1 \mathrm{~m}$ average contaminant concentration decreases by $45.1 \%, 1.7 \mathrm{~m}$ average concentration decreases by $46.4 \%$ and the total average concentration decreases by $42.5 \%$. 


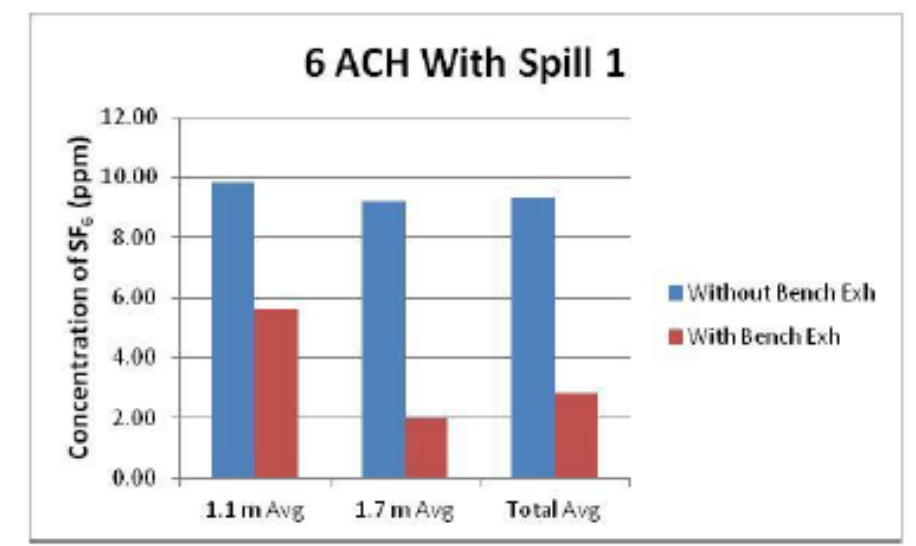

Figure 12: Average contaminant concentration without and with bench hood exhaust under $6 \mathrm{ACH}$ with spill 1 corresponding to cases 5 and 6

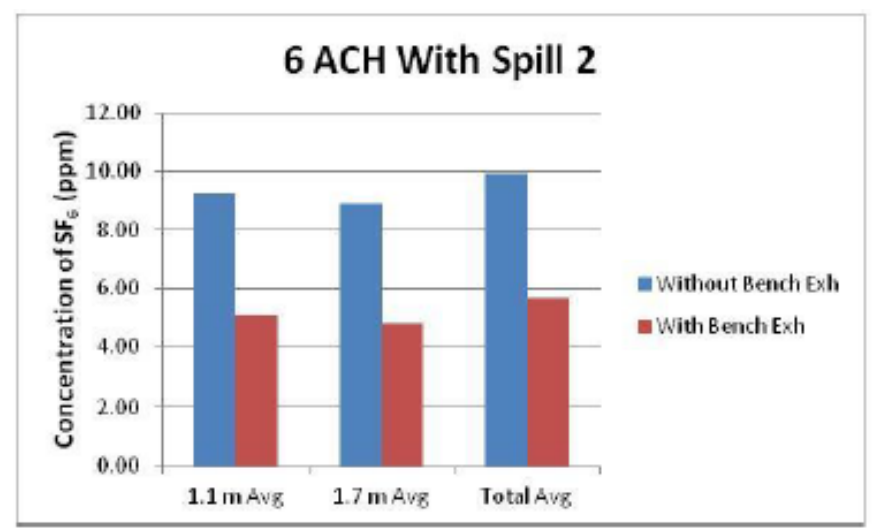

Figure 13: Average contaminant concentration without and with bench hood exhaust under $6 \mathrm{ACH}$ with spill 2 corresponding to cases 7 and 8

Very important conclusion will arise while comparing cases 1 and 6. Average contaminant concentration for cases 1 and 6 is depicted in figure 14. Although $12 \mathrm{ACH}$ is employed in case 1 compared to $6 \mathrm{ACH}$ in case 6 , the $1.7 \mathrm{~m}$ average contaminant concentration for case 6 decreases by $52.2 \%$ as compared to case 1 , and the total average concentration decreases by $31.1 \%$. On the other hand the $1.1 \mathrm{~m}$ average contaminant concentration increases by $37.2 \%$. Thus using the bench hood exhaust in case of bench spills may result that $6 \mathrm{ACH}$ may be comparable to $12 \mathrm{ACH}$ not employing bench hood exhaust.

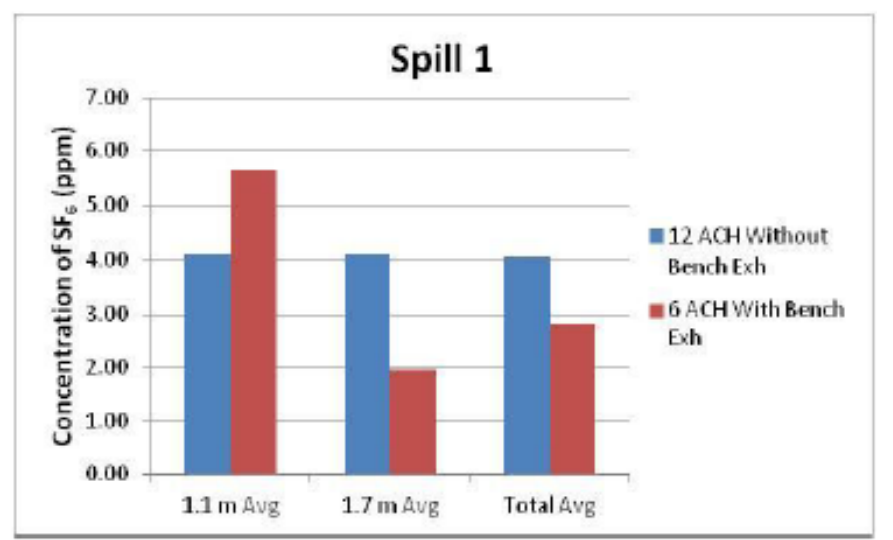

Figure 14: Average contaminant concentration for spill 1 without bench hood exhaust under 12 $\mathrm{ACH}$ and with bench exhaust under $6 \mathrm{ACH}$ corresponding to cases 1 and 6 


\section{CONCLUSIONS}

CFD is a powerful tool that can be used to simulate air flow pattern inside chemical laboratories and to compute contaminant concentration to the order of $10^{-7}$ mole fraction. This was clearly demonstrated through comparisons between the validation model and the corresponding experimental data. The average absolute percentage discrepancies were found to be less than $9.4 \%$.

Bench hood exhausts are very effective in capturing spills occurring on the bench top. This effectiveness is also obvious but to a lower extent when the spill occurs on the floor beside a standing occupant working in front of the bench. In a case with bench spill using the bench exhaust led to a decrease in the average contaminant in the sitting occupants' level by $64 \%$ and that of the standing occupants' level by $93.5 \%$.

Low ventilation rate as $6 \mathrm{ACH}$ with a well designed ventilation arrangement can be competitor to a traditional $12 \mathrm{ACH}$ ventilation system. This is extremely important conclusion keeping into consideration the energy saving accompanied by low ventilation rates. Using bench hood exhaust in a case of bench spill made the ventilation rate $6 \mathrm{ACH}$ comparable to $12 \mathrm{ACH}$ not employing the bench exhaust.

\section{References}

[1] Jin, M., Memarzadeh, F., Lee, K., and Chen, Q., Experimental study of ventilation performance in laboratories with chemical spills, Building and Environment, Volume 57, 2012, Pages 327 335.

[2] Memarzadeh, F., Effect of reducing ventilation rate on indoor air quality and energy cost in laboratories, Journal of Chemical Health and Safety, Volume 16, Issue 5, 2009, Pages $20-26$.

[3] Cheong, K.W.D., Djunaedy, E., Poh, T.K., Tham, K.W., Sekhar, S.C., Wong, N.H., and Ullah, M.B., Measurements and computations of contaminant's distribution in an office environment, Building and Environment, Volume 38, 2003, Pages 135 - 145.

[4] Rohdin, P., and Moshfegh, B., Numerical modelling of industrial indoor environments: A comparison between different turbulence models and supply systems supported by field measurements, Building and Environment, Volume 46, 2011, Pages 2365 - 2374.

[5] Chung, K.C., Tsai, K.P., and Wang, Y.H., Performance of local ventilated hood in a general ventilation working environment, ASHRAE Transactions, Volume 114, Part 1, 2008, Pages $424-430$.

[6] Lee, E., Khan, J.A., Feigley, C.E., Ahmed, M.R., and Hussey, J.R., An investigation of air inlet types in mixing ventilation, Building and Environment, Volume 42, 2007, Pages 1089 - 1098.

[7] Chau, O.K.Y., Liu, C.H., and Leung, M.K.H., CFD analysis of the performance of a local exhaust ventilation system in a hospital ward, Indoor and Built Environment, Volume 15, Issue 3, 2006, Pages $257-271$.

[8] Srebric, J., Vukovic, V., He, G., and Yang, X., CFD boundary conditions for contaminant dispersion, heat transfer and airflow simulations around human occupants in indoor environments, Building and Environment, Volume 43, 2008, Pages 294 - 303.

[9] Guyton, A.C., Textbook of medical physiology, Seventh edition, 1986, Saunders. 